\title{
Energy and macronutrient intakes of professional football (soccer) players
}

\author{
R J Maughan
}

\begin{abstract}
Objective-To examine the dietary habits of professional soccer players at two Scottish Premier League clubs during the competitive season.

Methods-A study of the dietary intake of 51 professional soccer players with two different clubs was carried out by the seven day weighed intake method.

Results-Physical characteristics of the two groups of players were similar, with only small differences in age and body mass but no difference in height and body fat. Mean (SD) daily energy intake for club A was 11.0 (2.6) MJ, and for club B 12.8 (2.2) MJ. The higher energy intake at club B was largely accounted for by a higher $(P<0.005)$ fat intake $(118 v 93 \mathrm{~g}$ $\left.\mathrm{d}^{-1}\right)$ : there was no difference in the absolute amounts of protein, carbohydrate, or alcohol consumed. When expressed as a fraction of total energy intake, mean protein intake was higher $(P<0.05)$ and fat intake lower $(P<0.01)$ at club $A$.

Conclusions-The mean energy intake of these players was not high compared with athletes in endurance sports. Fractional contribution of the macronutrients to total energy intake was broadly similar to that of the general population.

(Br F Sports Med 1997;31:45-47)
\end{abstract}

Keywords: soccer; football; nutrition; diet.

Regular training imposes extra nutritional demands on all sports participants, and the requirements of competition place an additional load on the individual. Total energy expenditure is increased in proportion to the amount of exercise performed, and the additional requirements for individual nutrients will also be increased by varying amounts. In locomotor sports where the energy demand is relatively easy to quantify, there have been several studies of the energy expenditure and nutrient intake of elite competitors: these sports include cycling, running, and swimming. The dietary habits of games players have, however, been less comprehensively investigated, and in spite of the universal popularity of soccer as a game, little information has been published on the dietary habits of soccer players. One estimate has suggested that there may be as many as 120 million players worldwide, ${ }^{1}$ and yet we know almost nothing of the dietary habits or nutritional status of elite performers in this sport.

The purpose of this study was to assess the energy and macronutrient intake of profes- sional soccer players at two Scottish Premier League clubs during a typical week of training and competition.

\section{Methods}

Subjects who volunteered to participate in this study were the playing staff of two successful Scottish Premier League teams. All players at both clubs took part, and all measurements were made at a time when players were in full training. Players prevented by injury or illness from training or competing at the time of the study, as well as those who had returned to match fitness within the previous week were excluded from the analysis, giving a total of 26 subjects at club $A$ and 25 subjects at club $B$. As well as recording food and drink intake, players kept a record of training undertaken and games played during the study week. All measurements were made at a time when players had one competitive game in the study week, and all data were collected within a four week period. The players included nine current and four former full international players, as well as reserve team players, giving a wide spread of age, playing experience, and ability.

All players weighed and recorded all food and drink consumed for a period of seven consecutive days. Players were issued with food diaries and digital scales readable to $2 \mathrm{~g}$ and with a comprehensive set of instructions on the procedures to be followed. Diaries were inspected after two days to ensure proper record keeping and to resolve any difficulties. The completed dietary records were analysed using a computerised version of the food composition tables of Paul and Southgate. ${ }^{2}$

Height, body mass, and skinfold thickness values were measured on all players in the morning before training. Percent body fat was estimated from skinfold thickness measured at four sites using the equation of Durnin and Rahaman. ${ }^{3}$

Data in the text and tables are expressed as mean (SD) throughout. Comparisons between the two groups of players were made by an unpaired $t$ test. Where the relation between variables within the players at a single club was examined, a least squares linear regression model was used.

\section{Results}

Physical characteristics of the players are shown in table 1 . The variation in playing experience of these players is reflected in the age range of 18-36 years. Players from club A were older $(P<0.02)$ and heavier $(P<0.01)$ but not taller than those at club $B$. There was no statistically significant difference in the esti- 
Table 1 Physical characteristics of players from the two clubs

\begin{tabular}{lcllcl}
\hline & \multirow{2}{*}{ Team $A$} & & & \multicolumn{2}{c}{ Team $B$} \\
\cline { 2 - 3 } \cline { 5 - 6 } \cline { 5 - 5 } & Mean & $S D$ & & Mean & $S D$ \\
\hline Age (years) & 26 & 4 & & 23 & 4 \\
Height (cm) & 178 & 7 & & 178 & 5 \\
Body mass (kg) & 80.1 & 7.8 & & 74.6 & 6.5 \\
Body fat (\%) & 12.2 & 2.4 & & 13.0 & 2.5 \\
\hline
\end{tabular}

mated percent body fat content of players at the two clubs.

Results for dietary energy and macronutrient intake are shown in table 2. Table 3 shows the contribution of the macronutrients to energy intake expressed as a percentage of total energy intake. The results reveal an energy intake somewhat higher than the average for the United Kingdom population, but the average composition of the diet is not different from the national average. In spite of the higher body mass of players in team $\mathrm{A}$, there was a lower total energy intake in these players $(P<$ 0.01 ). Dietary intakes of protein, carbohydrate, and alcohol were not different between the two clubs, but there was a lower $(P<0.005)$ fat intake in the diets of players at club A.

When the dietary intake of the macronutrients is expressed as a percentage of total energy intake, protein accounted for a significantly greater $(P<0.05)$ percentage of total energy for players at club A $[15.9(2.6) \%]$ than those at club B [14.3(2.0)\%]. Fat accounted for a smaller $(P<0.01)$ fraction of energy intake at club A [31.5(5.2)\%] than at club B $[35.0(4.1) \%]$. There were no significant differences in the fractions of total energy intake accounted for by carbohydrate or by alcohol at the two clubs.

\section{Discussion}

The training and competition programmes of the two clubs were similar and differences in training load seem unable to account for the observed difference in energy intake between the two sets of players. Because of the variations in the exercise intensity across the duration of training, no estimates of energy expenditure are available for these players. Reilly $^{4}$ estimated the daily energy expenditure during typical training of English professional

Table 2 Daily energy and macronutrient intake of players from the two clubs

\begin{tabular}{|c|c|c|c|c|c|c|}
\hline & \multicolumn{3}{|c|}{ Team $A$} & \multicolumn{3}{|c|}{ Team B } \\
\hline & Mean & $S D$ & Range & Mean & $S D$ & Range \\
\hline Energy (MJ) & 11.0 & 2.6 & $5.2-16.5$ & 12.8 & 2.2 & $8.5-16.2$ \\
\hline Protein $(\mathrm{g})$ & 103 & 26 & $59-154$ & 108 & 20 & $77-144$ \\
\hline Fat $(\mathrm{g})$ & 93 & 33 & $41-195$ & 118 & 24 & $74-179$ \\
\hline Carbohydrate (g) & 354 & 95 & $167-538$ & 397 & 94 & $243-599$ \\
\hline Alcohol (g) & 9 & 10 & $0-38$ & 13 & 9 & $0-28$ \\
\hline
\end{tabular}

Table 3 Percent contribution of macronutrients to energy intake

\begin{tabular}{|c|c|c|c|c|c|c|}
\hline & \multicolumn{3}{|c|}{ Team $A$} & \multicolumn{3}{|c|}{ Team B } \\
\hline & Mean & $S D$ & Range & Mean & $S D$ & Range \\
\hline Protein & 15.9 & 2.6 & $11.9-23.8$ & 14.3 & 2.0 & $10.8-18.5$ \\
\hline Fat & 31.5 & 5.2 & $19.2-41.2$ & 35.0 & 4.1 & $23.8-42.9$ \\
\hline Carbohydrate & 51.4 & 7.8 & $34.6-64.8$ & 48.4 & 4.4 & $38.3-58.4$ \\
\hline Alcohol & 2.3 & 2.7 & $0-10.5$ & 3.2 & 2.2 & $0-7.2$ \\
\hline
\end{tabular}

players to be approximately $6.1 \mathrm{MJ}$ (1500 kcal). The only technique that might be expected to give a reliable estimate of energy expenditure in a situation such as this is the doubly labelled water method, but this has not yet been applied to soccer players.

Energy intake is comparatively simple to measure, but only a limited number of studies on the energy intakes of players has been attempted. Comparisons between studies carried out in different countries must be made with some caution because of the differences in dietary habit among the normal population: dietary habits are also changing with time and this is especially true in sport, where an intensive education programme is encouraging athletes to adopt specific nutritional strategies. Where analysis of dietary records of soccer players has been undertaken, data for elite Danish players show a mean energy intake of 15.7 $\mathrm{MJ} \mathrm{d}^{-1}\left(3738 \mathrm{kcal} \mathrm{d}^{-1}\right) .^{5}$ Data reported for club players in Sweden give a daily energy intake of $20.7 \mathrm{MJ}$ (4930 kcal), but these measurements were made over only four days: these intakes were considered to be much less than the energy requirement of the players, based on body mass and activity profiles. ${ }^{5}$ Caldarone et $a^{t}$ also reported a rather low mean value of $12.9 \mathrm{MJ}$ (3066 kcal) for energy intake in 33 players competing in the top Italian division. In one individual English international player, Reilly ${ }^{7}$ recently reported a daily intake of $13.1 \mathrm{MJ}(3127 \mathrm{kcal})$. Dutch players competing at elite level were reported to have a mean energy intake of $14.3 \mathrm{MJ}$ $\mathrm{d}^{-1}\left(3406 \mathrm{kcal} \mathrm{d}^{-1}\right){ }^{8}$ In American college players, an energy intake of about $11 \mathrm{MJ} \mathrm{d}^{-1}$ was reported, but the standard of play of these individuals would have been considerably lower than those in the present study or in the other investigations referred to above. ${ }^{9}$

The mean values for energy intake in these Scottish players are generally lower than those in other published reports. This may be the result of deliberate or inadvertent underreporting of intake. One part of this may be the result of the emphasis on fitness for match play, and body mass and body composition undoubtedly have a bearing on this. In sports where a low body mass is crucial to performance, it is common to see underreporting of dietary intakes, ${ }^{10}$ although this seems to be much more common in female athletes than in males. Among the players in this study, there was a significant, albeit weak, negative relation between energy intake and estimated per cent body fat content among the players at club A $(r=-0.489$, $P<0.05)$, even though there was no relation between energy intake and body mass. In a previous study of female distance runners, a negative relation has been reported between energy expenditure (measured by doubly labelled water) and reported energy intake, suggesting that underreporting of energy intake occurs to a greater extent in the subjects training hardest: these were also the individuals most concerned with body image. ${ }^{11}$ The same may apply to some degree among elite performers in sport, even though none of the players in this study would be considered overweight. It seems likely that any underreporting of intake among these players was inadvertent 
rather than deliberate. An attempt was made to minimise this effect by interviewing players and inspecting their diaries after the first two days of record keeping, but the possibility of missing items cannot be excluded. There was no relation between estimated percent body fat content and energy intake at club B.

The absolute amount of carbohydrate in the diet may be an important factor for the recovery of the muscle and liver glycogen stores after training and competition. ${ }^{12}$ In a recent review of some of the nutritional demands of soccer, the authors stressed the need for a high carbohydrate intake, especially in the two to three days before competition: a carbohydrate intake of $10 \mathrm{~g} \mathrm{~kg}^{-1}$ body mass $\mathrm{d}^{-1}$ was recommended at this time. ${ }^{13}$ It is more usual, however, to focus on the carbohydrate content of the diet relative to total food intake. Although a diet in which about $50 \%$ of the energy is accounted for by carbohydrate may be considered satisfactory for the general population, this is somewhat less than the recommendations that are generally made for sportsmen and women, where a carbohydrate intake equivalent to $60-70 \%$ of total energy intake is considered appropriate. ${ }^{12}$ Recommendations for soccer players stress that a high carbohydrate diet is essential in training and in preparation for competition..$^{514}$ The mean values for diet composition in these players suggest a diet that is not different from that of the general population, and this finding is in accord with other reports for soccer players. $^{59}$ In elite Dutch players, carbohydrate accounted for about $47 \%$ of total energy intake. $^{8}$

The use of mean values in these reports does, however, obscure the extremely large interindividual variability that is often observed. Some players in the present investigation reported a carbohydrate intake of less than $40 \%$ of total energy intake, with the lowest individual value being $35 \%$. Even if the total intake is subject to errors resulting from underreporting, this should not significantly affect the composition of the diets. There seems little doubt that some of these players were consuming a diet that did not provide sufficient carbohydrate to maintain a high level of effort in training and competition. Several published reports suggest that many players begin a game with muscle glycogen levels that are less than optimal, ${ }^{15}$ and it seems clear that many players have an inappropriately low dietary carbohydrate intake. No attempt was made in this study to analyse diet in relation to competition to investigate possible changes in eating habits in preparation for match play: some of the players were involved in midweek games, and the differences in dietary habits between weekdays and weekend days would complicate the interpretation of the data.

The average alcohol intake of these players is rather less than the national average, and is broadly in accord with that observed in most studies of athletic groups. ${ }^{16}$ Again, however, this conceals the fact that some players reported high intakes, with the highest individual value being $11 \%$ of total intake. It is widely accepted also that alcohol intake tends to be underreported, and in some cases the intake may have been substantially higher than the reported intake. Ten of the 25 players at club $\mathrm{A}$ and four of the 25 players at club B reported zero alcohol intake during the week that diet was monitored.

Protein intake was highly variable between individual players, with a range from 59-154 g $\mathrm{d}^{-1}(12-24 \%$ of total energy) at club $\mathrm{A}$ and $77-144 \mathrm{~g} \mathrm{~d}^{-1}(11-19 \%)$ at club B. Protein intake is often expressed relative to body mass, and the intake at club A was $1.3(0.4) \mathrm{g} \mathrm{kg}^{-1} \mathrm{~d}^{-1}$, with a range of values from $0.8-2.1 \mathrm{~g} \mathrm{~kg}^{-1} \mathrm{~d}^{-1}$ : at club $\mathrm{B}$, the mean daily protein intake was $1.5(0.2)$ $\mathrm{g} \mathrm{kg}^{-1} \mathrm{~d}^{-1}$ with a range of values from 1.1-1.8 $\mathrm{g}$ $\mathrm{kg}^{-1} \mathrm{~d}^{-1}$. Lemon ${ }^{17}$ has recommended a daily protein intake of $1.4-1.7 \mathrm{~g} \mathrm{~kg}^{-1}$ as being adequate for soccer players, and although some players fell below this recommended intake, all were at or above the recommended intake for the general United Kingdom population of 0.8 $\mathrm{g} \mathrm{kg}^{-1} \mathrm{~d}^{-1}$.

In summary, these results show a pattern of dietary intake in elite professional soccer players that is not very different from that of the general population in the United Kingdom. There were some small differences between the two clubs studied, but in general the pattern of energy and macronutrient intake was the same in both clubs. It seems clear that some players consume a diet that supplies less carbohydrate than is normally recommended to sustain performance in training and competition. The diet of other players, however, seems entirely adequate to meet their needs, and any recommendations for dietary modification should be targeted at individual players only after an assessment of current intake has been made.

I gratefully acknowledges the assistance of the management and playing staff of the two clubs where this work was carried out.

1 Ekblom B. Applied physiology of soccer. Sports Med 1986;3:50-60.

2 Paul AA, Southgate DAT. The composition of foods. London: HMSO, 1988.

3 Durnin JVGA, Rahaman MM. The assessment of the amount of fat in the human body from measurements of skinfold thickness. Br f Nutr 1967;21:681-9.

4 Reilly T. What research tells the coach about soccer. Washington DC: AAHPERD, 1979.

5 Bangsbo J. Fitness training in football. Bagsvaerd: HO+Storm, 1994.

6 Caldarone G, Teanquilli C, Giampietro M. Assessment of the nutritional state of top level football players. In: Santilli the nutritional state of top level football players. In: Santilli G, ed. Sports

7 Reilly T. Physiological aspects of soccer. Biol Sport 1994;11: 3-20

8 van Erp-Baart AMJ, Saris WHM, Binkhorst RA, Vos JA, Elvers JWH. Nationwide survey on nutritional habits in elite athletes. Part 1. Energy, carbohydrate, protein and fat intake. Int $\mathcal{F}$ Sports Med 1989; 10; S3-S10

9 Short SH, Short WR. Four-year study of university athletes' dietary intake. $\mathcal{A}$ Am Diet Assoc 983;82:632-45.

10 Burke L, Deakin VA. Clinical sports nutrition. Sydney: McGraw Hill, 1994.

11 Edwards JE, Lindeman AK, Mikesky AE, Stager JM. Energy balance in highly trained female endurance runners. Med Sci Sports Exerc 1993;25:1398-404.

12 Coyle E. Timing and method of increased carbohydrate intake to cope with heavy training, competition and recovintake to cope with heavy training, competition
ery. $\mathcal{F}$ Sports Sci 1991;9(special issue):29-52.

13 Hawley J, Dennis SC, Noakes TD. Carbohydrate. fluid, and electrolyte requirements of soccer play: a review. Int $\mathcal{f}$ electrolyte requirements of
Sports Nutr 1994;4:221-36.

14 Hargreaves $M$. Carbohydrate and lipid requirements of soccer. $\mathcal{F}$ Sports Sci 1994;12:S13-16.

15 Shephard RJ, Leatt P. Carbohydrate and fluid needs of the Shephard RJ, Leatt P. Carbohydrate and fluid
soccer player. Sports Med 1987;4:164-76.

16 Economos CD, Bortz SS, Nelson ME. Nutritional practices of elite athletes. Sports Med 1993;16:381-99. 17 Lemon PWR. Protein requirements of soccer. F Sports Sci 